\title{
THE MILITARY GLIDER REVISITED
}

\section{Helmoed-Römer Heitman*}

The military glider has, arguably, enjoyed the briefest life span of any major military equipment type - spanning not much more than a decade and a half from the entry into production of the first, to the demise of the concept as such. During its heyday, however, the glider was instrumental in not a few spectacular operations. Thus, it is not really surprising that some of the more iconoclastic military thinkers have, albeit infrequently, wondered whether there is not still a place for up to date gliders in modern warfare.

Just over one year ago, Lieutenant McGill Alexander addressed this question in an article in Militaria, reviewing the glider's primary characteristics and suggesting that these might merit serious consideration of the glider as a complement to paratroops. Interestingly, he also touched on the possibility of employing gliders in the resupply of fast moving mechanised forces. This article will outline several other possible applications of the military glider in the Southern African context, addressing both low intensity and conventional war.

Before setting out to do this, it is perhaps as well to briefly review the glider's salient characteristics. In essence, it has many of the capabilities of the helicopter which, in fact, largely supplanted it. Its disadvantage relative to the helicopter is that it allows only for delivery, a different means of extraction being required. On the other hand, the glider can project power to much greater ranges than even the latest helicopters. Setting out its salient characteristics in point form, we have:

- Long range, limited only by the range of available transport aircraft and air support;

- Extreme accuracy of placement;

- The ability to deliver a concentrated group of men ready to go into action;

- The ability to deliver heavy equipment;

- The ability to deliver concentrated supply loads;

- The ability to land on quite rough and very short unprepared pieces of more or less level ground;

- Relative imperviousness to local weather conditions;

- Relative expendability resulting from relatively low cost and simplicity, the latter also allowing local development and production.

- Little or no requirement for specialised training on the part of the troops to be landed, allowing normal infantry to be so employed after basic orientation and thereby freeing paratroops for more specialised tasks.

- A degree of immunity to current air defences, having no infrared and only - depending on construction - a low radar signature;

- The ability to deliver a measure of suppressive fire during the landing phase by means of fixed or flexibly mounted machine guns ${ }^{1}$ or possibly even underwing rocket pools ${ }^{2}$.

- The possibility of co-inciding the landing phase with a preparatory air strike, and

- The related ability to land its passengers on the objective to be assaulted without incurring unacceptable risks.

Applying these characteristics in the southern African situation, we can find applications both in the external element of COIN operations and in more conventional warfare.

In the former case, one result of our successful raids against PLAN bases in southern Angola has been to force their relocation deeper into that country. The disadvantages of this to PLAN are readily apparant, but there are also disadvantages to ourselves which are less so.

Then, too, we face the situation that distance will increasingly hamper the employment of heliborne assault until the stage is reached where usefully laden helicopters might well be able to reach the objective, but would be unable to return without refuelling. This will then leave us with rather restricted options:

- An entirely overland raid;

- A paradrop near the objective;

- A heliborne raid relying on refuelling on the objective or

- A combination of any of the above.

None of these will be without serious disadvantages.

Thus, an overland raid would inevitably be so well advertised that, far from achieving any 


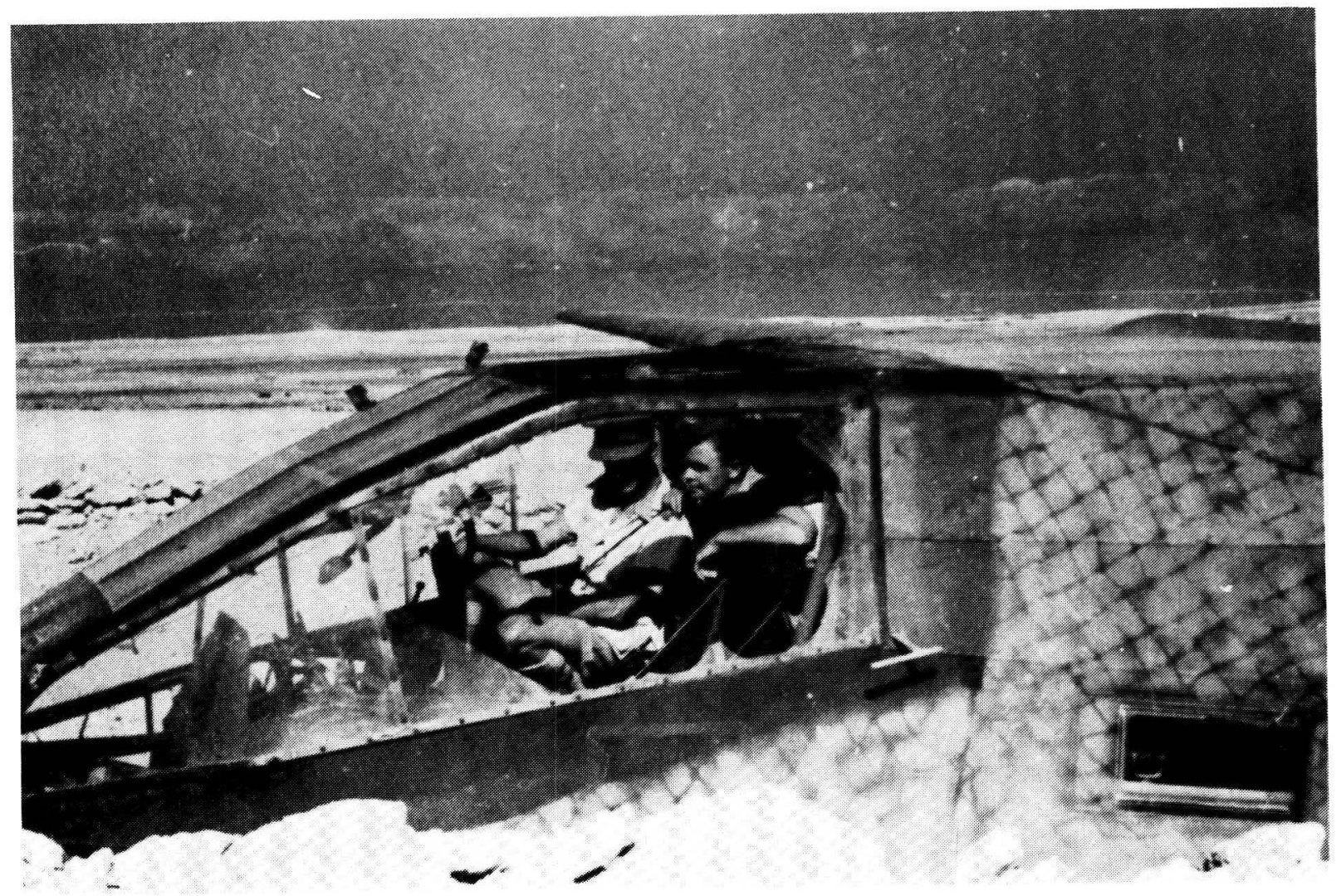

German Tank carrying a glider WW II

worthwhile measure of surprise, the raiding force could very well find itself ambushed and/or cut off by a superior force. Such a force could not only be superior in terms of size, but also in terms of the type of equipment deployed as it would, in effect, be operating on interior lines. Also, the further such a raiding force penetrates, the greater will be its vulnerability to air attack as the SAAF's ability to provide a continuous CAP at long range would be limited. At the very best, such a raid would encounter fully prepared and alerted defences. Instead of a short, sharp almost surgical - strike, we could thus find ourselves faced with a very messy and potentially costly imbroglio that would serve only to provide the enemy with a welcome source of propaganda material.

A paradropped raiding force could well - by dint of low flying during the approach - achieve a measure of surprise but would face several other serious problems. Thus a very low level drop would go some way towards delaying discovery but would require extremely accurate navigation and also carry with it a not inconsiderable risk of serious injury problems. A more conventional

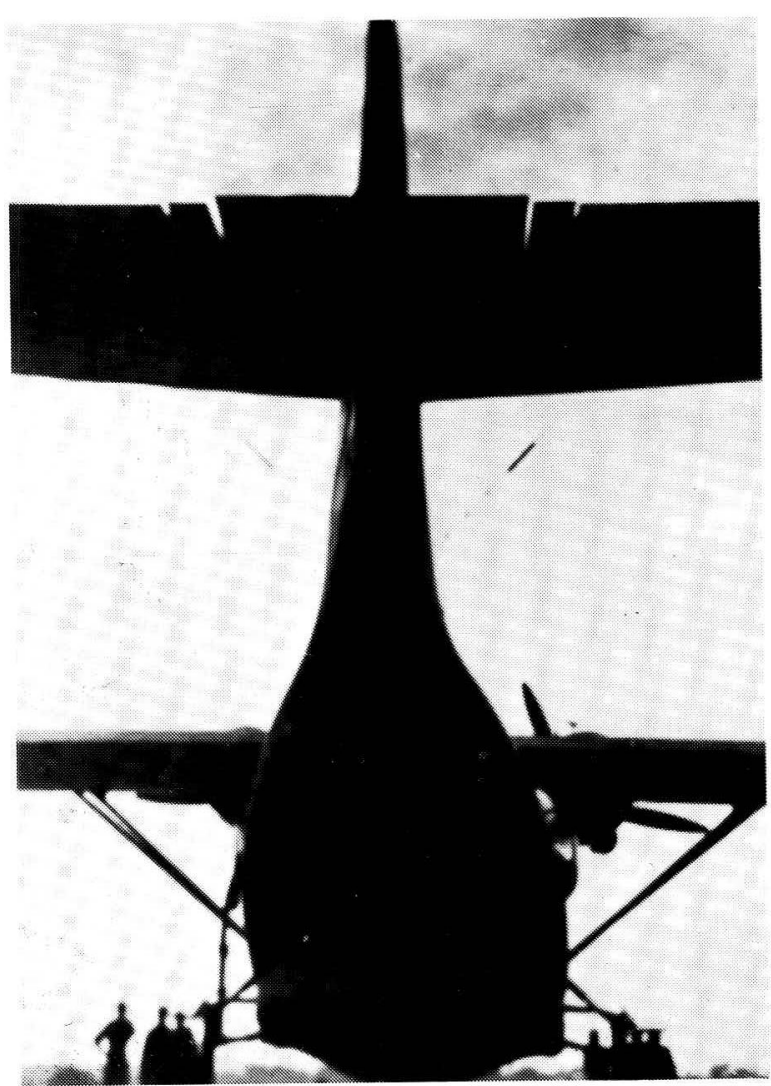

Example of a Horsa Glider 
drop, on the other hand, would almost certainly result in the transport aircraft being acquired by the local air defences, which could prove unacceptably costly. Then, too, the sound of the aircraft would in either case serve to alert the garrison unless the $D Z$ is some distance from the objective - which would in itself create additional problems.

Once on the ground, such a raiding force would be highly vulnerable to any interference at all until it has successfully consolidated. Even then, it will remain painfully vulnerable to any mechanised force until and unless at least some heavy equipment can be dropped. Unless the terrain and the enemy situation allow low-level extraction techniques to be employed, this will however, only be possible after the local air defences have been neutralised. A paradropped raiding force might well also experience difficulty in overcoming the alerted defences, lacking as it would, any integral heavy support.

Finally, there remains the question of extraction, although this could probably be quite readily handled by helicopter - if a sufficiently secure LZ can be established. This would be of particular importance if the raid was carried out at extreme range, as the helicopters might then have to be refuelled on the ground. In turn, this presents another set of problems - that of accurate (ie within the $L Z$ ) fuel delivery and its handling on the ground - should the helicopters not be able to carry sufficient fuel as cargo on the way to the objective.

The vulnerability of a heliborne raid relying on refuelling on the objective for its extraction, is sufficiently apparant not to warrant further discussion here. Suffice it to say that one major problem would be the delivery of the fuel in the absence - which must be assumed in the case of a large raid - of sufficient helicopters to transport both the raiding force and the necessary fuel.

While a combination of these approaches would go a little way towards ameliorating some of these problems, none would be entirely satisfactory as the essential weaknesses would remain: the obviousness of a ground force on a long approach; the extreme vulnerability of unsupported paratroops and the range - and number! - limitations of helicopters. It is in this context that the concept of the assault glider would appear to merit serious consideration as an element of cross-border deep-penetration raids.
A glider-borne deep-penetration raid might, thus, take the following form:

- An extremely low level approach by the towed gliders to the release point, thereby seeking to underfly the opposing surveillance system, a fighter and/or flak suppression escort being provided if deemed necessary;

- An equally low approach by seperate and later starting successive strike and ground support forces;

- Gliders released some ten minutes from the objective, using JATO type rocket assistance to 'pop up' to an altitude from which they can acquire and reach the objective ${ }^{3}$, then diving towards it, the towing aircraft returning to base at low altitude;

- A preparatory strike on the objective timed to co-incide with the assault force coming within earshot of the objective, thereby distracting the defenders' attention from the sound and sight of the JATO 'pop up' and, if necessary, the sound of the towing aircraft. ${ }^{4}$ This strike would employ exclusively cluster, fragmentation (free-fall or rockets), fuel-air or napalm weapons and cannon fire in order to minimise the danger of significant terrain-deformation which could endanger the landing gliders;

- The gliders land on the objective immediately after the preparatory strike and under cover of ground support aircraft which, being relatively manoeuverable at low speeds could continue to engage the ground defences during the landing phase. They would use drogue chutes and/or retro-rockets to reduce their landing run to a minimum. ${ }^{5}$

- The assault force disembarks and goes into action under the continued cover of ground support aircraft and using whatever heavy equipment has been brought in in assault or cargo gliders. This could well include heavy mortars, light guns and Eland-90s.

- Relieving ground support aircraft stand off, coming in to deal with indicated targets as the assault force proceeds to clear the objective of the enemy.

- Once the assault force has accomplished its mission, helicopters are brought in to extract it, refuelling if necessary from fuel carried as cargo on the run in to the objective or landed in cargo gliders. The gliders and equipment too heavy to be lifted out are destroyed and/or booby trapped. Ground support aircraft cover the extraction and, together with fighters, escort the returning helicopters. Where sufficient level ground is available, undamaged gliders could be picked up by their towing aircraft, 
which would also allow for the extraction of heavy equipment - such as Eland 90 s - and captured items of interest. ${ }^{6}$ In the event of an airfield being available on the objective, extraction would, of course, be still more simplified.

In the event of a raiding force being intended to operate in the vicinity of the objective for some time, both attack and medium helicopters could be operated from the original objective, being supplied with fuel and spares by glider or parachute as convenient or most practical. The remainder of the force could then be supplied similarly, with delivery to some elements perhaps handled by the forward based helicopters. In such a case, the necessary forward maintenance/repair facilities for all types of equipment could be provided by flying suitably equipped cargo gliders into the objective. ${ }^{7}$ Covered and properly equipped and fitted workshop facilities could thus be provided, easing the vehicle and equipment maintenance problem and eliminating the need for the forward based helicopters to return to their home base for any but major overhauls.

A raid such as that set out above, would naturally only be justified by a major base or base area and there is probably a lower limit below which such a glider-borne raid might no longer be an efficient approach. This limit will, however, be set as much by the importance of the particular objective as by its simple size. Taking a different approach, a glider-borne raid could well also recommend itself in the case of an objective that is within helicopter range but where absolute surprise is essential. In such a case, a small raiding party could be inserted by glider, arriving silently without a preparatory strike but perhaps enjoying air support once on the objective and then being speedily extracted by helicopter. Such an approach might, for instance, be used where the intention is to seize a particular prisoner or item of equipment.

Considering the glider-borne raid in comparison to the other options outlined earlier, we find that it offers:

- A greater measure of surprise than any but, perhaps, a direct heliborne assault;

- Potentially reduced vulnerability by comparison with a heliborne or paradropped raiding force.

- Greater depth then could be achieved by a purely heliborne assault.
- Considerably less risk of losing irreplaceable aircraft than either a heliborne assault or a paradrop: other than the strike and ground support aircraft - which are at equal risk in any event - the only aircraft exposed to the air defences at the objective are the gliders. These would, in fact, in all probability prove relatively invulnerable to these air defences they would have no infra-red signature to speak of (the JATO pods would be dropped well clear of the objective), are silent in their approach and would be flying a rather unexpected profile which would serve to further confuse anti-aircraft gunners and would in all probability have a very low radar signature. Once on the ground, their landing run would be extremely and thus unexpectedly short and the retro-rockets would help cover the disembarkation phase. Then, too, they could deliver a measure of suppressive fire themselves and their landing could be covered by ground support aircraft (which is somewhat more difficult to achive in the case of a paradrop). Finally, the gliders, if not their passengers, would, after all, be expendable. To bring back a glider is nice, to lose one is acceptable; to lose a Puma or a C-130 is far from acceptable.

Summing up, a glider-borne deep-penetration raid would offer all the advantages of both a heliborne and a parachute raid while greatly reducing their inherent disadvantages.

Considering a possible conventional assault on the Republic, this situation, too, would appear to offer not inconsiderable scope for airborne operations. In any of these, the employment of gliders could again offer significant advantages over the more conventional parachute delivery. In this regard it is perhaps as well to recall that General Student - in effect the founder of the German airborne forces - felt that large scale parachute operations were too costly in lives for the benefits that they might offer. Another point that he made very strongly in this regard, is that the formation of large specialised airborne elements has a deletrious effect upon the rest of the army by drawing away too high a proportion of the best combat personnel. Both of these considerations are, of course, to a large measure addressed by the glider.

The aim of any conventional assault on the Republic would have to be to engage and destroy our manoeuvre elements, thereby seeking to create a favourable situation for a revolutionary 
take-over of power by the selected parties. The realities of force: space ratios and logistic problems would render any attempt at a more conventional invasion/occupation far too costly for it to be worthwhile in the foreseeable future. We would thus not face a 1939/45 style war but rather something more closely akin to the early operations by the Boer forces before they allowed themselves to be drawn into static warfare - in effect columnar warfare of the type that can also be found much further back in military history.

In brief, such an assault would seem likely to take the form of multiple high-speed thrusts by armoured/mechanised forces towards the vital Rand area, thereby drawing and engaging our manoeuvre elements. For the destruction of these, the attacker would rely on armour superiority and the exploitation of his initiative to achieve a defeat in detail. These semi-conventional operations would be accompanied by widespread, thoroughly orchestrated civil disobedience, rioting, sabotage, urban terrorism and rural guerilla operations. These would serve not only to distract and hamper us, but also to prepare the way for a takeover once the conventional phase is completed. In this way, a relatively small attacking force would hope to achieve its aim and, if not swiftly and imaginatively countered, might in fact be able to do so. Of necessity, the above outline is extremely sketchy and over-simplified. It should, however, suffice to set the scene and it certainly does match with current Soviet doctrine concerning conventional operations.

Two of the major problems facing such an attacker would result from the sheer size and from the great distance of the southern African theatre: an extremely poor force: space ratio and some extremely long lines of communication. In combination, these would appear to offer us a plethora of highly lucrative and vulnerable targets. Vulnerable because the enemy will hardly be able to spare many effective combat elements for rear area security and highly lucrative because the aforementioned distances will render him almost uniquely vulnerable to any disruption of his logistics. This, latter, particularly also in view of the fact that his force will be relatively smaal by comparison with our overall capability, which any delay on his part will facilitate our mobilising and concentrating

For ourselves, it will be essential that we borrow from what is today Soviet doctrine and imme- diately engage the enemy over his entire depth. Only in this way can we reasonably expect to balance out his armoured superiority and to impose sufficient friction upon him to allow an effective overall response. Raiding by ground forces is likely to be the most effective way of achieving this aim.

Some such raids could, of course, be carried out overland by means of small mechanised combat teams passing into the enemy's rear between his advancing columns. One possibility that springs to mind here, would be to employ suitably modified 'long range' Ratel-20s, 90s and 81s together with the appropriate support vehicles. Resupply during the course of such a raid might well be by air, where the glider could play a major role. Over shorter distances, heliborne raids also offer considerable potential, although many if not most of our scarce helicopters would in all probability be fully engaged in supporting the initial covering-force battles and the later counterthrusts. Raids to greater depth would in any event have to be either parachute or glider inserted.

Some possibilities for airborne operations of all three basic types would include:

\section{During the initial defensive phase:}

- The movement of forces of varying sizes to seize terrain ahead of advancing enemy columns where time does not allow for overland movement;

- The seizure of choke points behind the advancing enemy columns in order to hamper their resupply and reinforcement;

- Raids against enemy dumps, installations, airbases and headquarters;

- The positioning of scouts, observation and target designation teams in the enemy's rear;

- The insertion of light mobile raiding groups in the enemy's far rear in order to begin disruption of his logistics and

- The establishment of temporary airheads in the enemy's far rear to support and control raiding groups harrassing his lines of communication.

During the subsequent counter-offensive phase, possible additional operations might include:

- The seizure of terrain and/or installations vital to our advance and/or to the enemy's withdrawel;

- The establishment of expanding airheads on 
our axes of advance and/or on the enemy's withdrawel axes;

- The establishment of expanding airheads in the enemy's far rear and

- The seizure of airfields in the enemy's rear and the establishment of expanding airheads on these.

In most of these possible operations, gliders could offer considerable advantages over parachute delivery both during the initial assault or insertion and later in the resupply role.

Most importantly, they would allow the employment of normal infantry and other elements, thereby freeing fully trained paratroops for more specialised missions or for operations beyond helicopter range but where terrain does not allow the employment of gliders. The use of suitable gliders could thus greatly expand our potential for airborne operations and thereby add considerable flexibility to our operations and enhance our ability to speedily engage the enemy over his entire depth. The great operational mobility of gliderborne forces would also allow their deployment from far to the rear which would serve to ease our mobilisation problems by freeing forward elements from many raiding tasks.

Naturally, such operations would require varying degrees of at least temporary local air superiority if they are to be practicable. In this regard, it must be remembered that much of the enemy's air power would, in the opening phase at least, be fully engaged in counter-air operations and the support of his own advancing columns. Assuming that the enemy does not succeed in gaining air supremacy during this stage, the situation should, at worst, remain the same during our later counter-offensive phase; at best, we might have full air supremacy. At this point it might be argued that once we have air supremacy, there would no longer be any need for such raiding operations. The reply to this is, of course, that air power alone will not be sufficient - one need merely consider the German Army's continued ability to operate in the face of absolute Allied air supremacy after the 1944 landings or the October 1973 war.

In any event the application of airborne operations during a counter-offensive phase would serve to greatly speed up the enemy's collapse. Not only would this serve to save lives - and money! - it might well also serve to preclude the enemy's backers making good their initial false assessment by rushing in reinforcements, not least aircraft.

Most of the possible airborne operations listed above would be more or less conventional in execution and there are ample historical examples of such raids and operations available. They will, therefore, not be further discussed here except to once again stress the potential advantages of gliders in such operations - advantages that will be apparent from a comparison of the glider's characteristics with each individual mission's requirements. Two aspects that do seem to merit further discussion, however, are the insertion of mobile raiding forces into the enemy's far rear and the concept of the expanding airhead.

As has been discussed above, one of the major problems facing a conventional attacker will be his inordinately long and vulnerable lines of communication. The effect of small mechanised raiding groups roaming the enemy's rear under these circumstances, can be readily imagined. Unfortunately, overland penetration into the enemy's far rear will not be a practicable proposition if only because of the time factor - such penetration would take several days before the force was far enough in to begin operating; days that we will not be able to afford. Given suitable vehicles, however, there is no reason why the insertion should not be by air. Vehicles such as the Eland series or a possible successor family would seem ideally suited to this role.

While parachute delivery is possible, this would normally require the transport aircraft to climb to an altitude where they might all too easily be acquired by surveillance radars. Low-level extraction techniques might be useable but could result in unacceptable losses on unprepared veld. Gliders, on the other hand, would not even need to 'pop up' as in the raid previously described as in this case pinpoint accuracy of landing would not be required. Considering southern Africa's topography, there should also be no shortage of potential landing zones. The towing aircraft and any escort, could fly low on both legs of the insertion. Another advantage of glider delivery would again be that the vehicles and crews would be guarranteed to arrive together, which will speed up the reaction to any unforseen events on the ground. A small pathfinder team might have first to be inserted in a low-level drop.

Once landed, such small (perhaps around a 
dozen vehicles) raiding groups would set out to conduct hit and run raids, ambushes and minelaying over a large assigned area. Potential targets would include road convoys, trains, dumps and installations, communications facilities and possibly even rearward airfields. For their security such forces would rely on:

- Their mobility;

- The small size and low signatures of their vehicles as well as the difficulty the local population would have in telling one light armoured vehicle from another;

- The lack of serious opposition;

- The low population density in many of the likely areas and the lack of effective communications and

- Most importantly, the simultaneous operations by several such groups as well as by other raiding groups closer behind the actual area of major operations which, together, would confuse and distract the enemy and hinder his concentration against any one of them.

One possible vehicle mix for such a force would comprise Eland (or successor model) 20s, 90s, a turretless version fitted with an $81 \mathrm{~mm}$ mortar and a few logistic vehicles, probably 1 or 2 tonne trucks.

As an area becomes untenable or unrewarding, the raiders could move on or be extracted depending upon the current situation. During the operation itself, resupply would be by means of paradrop or glider as is appropriate in each case. Replacements and replacement vehicles could be similarly delivered. Final extraction and the extraction of wounded or sick personnel would present some difficulties which need not, however, be unsurmountable. Depending on the location of the force at the time when extraction becomes necessary, this might well be possible by helicopter - additional fuel either being delivered previously or being carried as cargo by the helicopters on the way in. This would, of course, entail the abandonment of the vehicles although critical items of their equipment could be taken out with the personnel. Casevac might be similarly handled.

Should a road or other suitable terrain be available, extraction could be by means of transport aircraft or landed and recovered gliders. In this case, the vehicles could, of course, also be recovered if sufficient time is available. Casualty extractions could also be handled by light aircraft fitted for long range operation and using roads or other flat ground to land on. Other means of extraction could be by sea or by the raiders moving under their own power overland and through the area of main operations back to our own lines. In fact, final extraction might not be necessary until after the enemy's collapse, when it would be a fairly peaceful exercise. Apart from the potential extraction problem, such raiding groups would probably be at less risk than many of the more conventionally employed units. Where distance/payload factors might preclude even the insertion of even light armoured vehicles, armed and suitably equipped Land-rover type vehicles could be employed in their stead. These would merely have to be somewhat more circumspect in their choice of target and means of engagement.

Suitably orchestrated as a system, the three types of raiding forces - long range Ratels penetrating the combat zone overland and operating in the enemy's immediate rear, airlanded Eland type vehicles in his far rear and light vehicles in his extreme rear - could come close to bringing about a total collapse of the enemy's zone of communications. This would seriously slow down the operations - be it his advance or later withdrawel - and also force the diversion of scarce combat elements in an attempt to deal with the problem. This, in turn, would weaken his forward forces and could go some way towards allowing a major thrust by our manoeuvre forces. A relatively small investment of men and equipment could, therefore, have a major and lasting effect on the enemy's operations.

A more ambitious approach would be the establishment of airheads in the enemy's rear as indicated above. Where security considerations would allow the establishment of these for a period, they would allow markedly more intensive raiding operations to be conducted. In some cases, it might even be possible to fly in helicopters to expand the area of operations by ferrying supplies to the raiding parties or even combat helicopters to operate in their own right. As it becomes plain that the enemy is about to put serious pressure on such an airhead, it could either be totally extracted - by means similar to those discussed above - or be relocated to a safer and/or more fruitful area. In each case the raiding groups that the airhead has been supporting would operate as independant groups resupplied directly by air until they, too, are extracted or move into the area of another - or the relocated - airhead. 
The airheads envisaged here would not be particularly large and would ideally be fully mobile, comprising only the bare minimum of maintenance, medical and command personnel necessary to control and support the raiding operations in their area. An at least temporarily fixed one would, of course, have advantages. Thus, suitably equipped gliders could be flown in to be used as workshops, dressing stations and communications centres and it could even be possible to bring in equipment to level an area large enough to allow powered transport aircraft to land. The specially fitted gliders would naturally be extracted and moved with the airhead but would hardly be worth establishing in an airhead that moves every day or so. In such a case a minimum of suitably fitted containers/shelters might be airlanded during the initial establishment and thereafter moved by the attached helicopters or on light trucks as necessary. The same would apply to other equipment such as bladder tanks and some essential vehicles, such as small front-end loader/forklift combinations. Other vehicles could then move overland.

Security for a new site could initially be provided by one of the raiding groups until the airhead is fully established. It might also pay to keep some armoured vehicles in the immediate vicinity as a matter of policy in order to assist in the defence of the airhead should it come under ground attack. Air defence would be provided by light equipment moving with the airhead. Apart from Redeye/Strela type weapons, truck mounted $20 \mathrm{~mm}$ guns could be inserted, as could more sophisticated types of equipment if available. The initial establishment of such an airhead would follow much the same sequence for the glider-borne raid except that it would not involve enemy contact. A strike/ground support force should none the less be on hand as a precaution unless one or more raiding groups are physically on the LZ. The latter approach would also eliminate the need for a prior insertion of pathfinders.

Once our manoeuvre forces have gone over to the counter-offensive, the airhead approach could be taken a step further by using enemy airfields as the basic site, after an airborne assault to seize them. Once established, such an airhead would then even allow for the employment of fixed wing ground support aircraft against the enemy's lines of communication. Strike aircraft might even conceivably be refueled and armed at such an airhead in order to allow strikes even deeper into the enemy's rear while remaining based at their home bases for maintenance purposes. Taking the airhead concept to this extreme would, of course, only become feasible once the enemy is clearly seen to be at his limit or - alternatively - as a desperate measure should we be at ours. In the case of all of the airhead type operations, the risks could be great but they would also be calculable with a fair degree of accuracy - the potential rewards could be well-nigh incalculable. While they would be possible using conventional parachute delivery, it would be the use of gliders that would make such operations really practical propositions once given the right conditions.

Having put forward several possible employments of gliders in our defence, it is necessary also to briefly look at what types of gliders we might need. In fact, this could be kept down to two basic types with some of these then being fitted out for the various specialised applications:

- A small, highly manoeuvreable assault glider able to transport ten to twelve troops and their equipment and possibly a small amount of additional cargo. Ideally, this glider would have provision for some limited armament in order to allow it to participate in the suppression of the defences during an assault landing.

- A larger, cargo glider capable of delivering between seven and ten tonnes of equipment including light armoured cars.

Both would need to be sufficiently rugged to allow recovery where this is allowed by the terrain. Both might also advantageously be so designed as to allow the ready development of powered versions should these prove desireable or necessary - in the face of improved enemy air-surveillance/defences for instance, which would dictate earlier release. A version of the cargo glider suited to the delivery of containers would probably also merit serious consideration. Other specialised versions could utilize the basic fuselage, merely incorporating the necessary fittings and equipment.

Totally seperate from these, but meriting consideration, is the possibility of a small powered glider for surveillance operations, particularly in couterinsurgency. The basic concept was tried apparantly with some success, in great part due to its silence - by the Americans in Vietnam and it certainly does seem to offer potential in our case. In the long run, one could also foresee remotely-piloted versions for various tasks.

Almost certainly there will be not a few readers of 
the above who will be certain by now that the writer has taken leave of his senses - or perhaps that he is a 'parabat' who has landed on his head once too often. The writer believes - hopes? that the former is not the case. As regards the latter, he has grave doubts as to whether anything short of a major disaster would ever persuade him to exit an aircraft without the benefit of boarding stairs! Glider operations he would find rather more palatable.

Returning to the serious, some of the above suggestions will certainly appear rather wild at first glance and they will equally certainly bring with them many problems that the writer has not even been able to conceive of, before they could become practicable. On the other hand, those who first suggested dropping troops out of aircraft in flight with only a small scrap of silk to slow down their descent, must also have caused some doubts among their contemporaries as, indeed, did the initial backers of the glider. Certainly the one time commander of Eben Emael, should he still be alive at this time, would be inclined to at least take a close and serious look at these suggestions before - perhaps - casting them into the outer wilds of the circular file. Then, too, he might find some merit in them.

It is the writer's hope that this will be the spirit in which they are read - as an initial reconnaissance of new ground intended to provoke discussion, thought, further writing and, perhaps, in the long run, some action.

*Helmoed-Römer Heitman, BA (Econ)(UCT), B. Soc. Sci.(Hons)(Pub Adm) (UCT), MA (War studies)(London)

\section{Footnotes}

1. As was done with several WW II German gliders. The light DFS 230, for instance was on occasion fitted with a roof-mounted flexible MG and/or two fixed MGs in the nose.

2. Although turbulence problems could arise here.

3. Several experiments were conducted successfully during WW II with various similar methods of extending the gliders autonomous flight time although this 'pop up' is to the writers best knowledge, a new approach.

4. The latter will depend on the distance from the objective at which the gliders can safely be released.

5. In the case of the 9 passenger DFS 230, a combination of drogue chute and three retro-rockets reduced the landing run to between 14 and 18 Metres.

6. This was carried out repeatedly during WW II by means of the towing aircraft hooking the suspended - between poles - bridle in a low pass.

7. As was regularly done by the Luftwaffe's tactical and transport units during WW II. 